Article

\title{
General and Simple Decision Method for DG Penetration Level in View of Voltage Regulation at Distribution Substation Transformers
}

\author{
Il-Keun Song ${ }^{1}$, Won-Wook Jung ${ }^{1}$, Chul-Min Chu ${ }^{1}$, Seong-Soo Cho ${ }^{1}$, Hyun-Koo Kang ${ }^{1}$ \\ and Joon-Ho Choi ${ }^{2}$ *
}

1 Korea Electric Power Research Institute (KEPRI), Korea Electric Power Company (KEPCO), 105 Munji-Ro, Yuseong-Gu, Deajeon 305-760, Korea; E-Mails: songilk@kepco.co.kr (I.-K.S.); wwjung@kepco.co.kr (W.-W.J.); cmchu79@kepco.co.kr (C.-M.C.); onlycho@kepco.co.kr (S.-S.C.); khyun9@kepco.co.kr (H.-K.K.)

2 Department of Electrical Engineering, Chonnam National University, Gwangju 500-757, Korea

* Author to whom correspondence should be addressed; E-Mail: joono@chonnam.ac.kr; Tel.: +82-62-530-1742; Fax: +82-62-530-1749.

Received: 4 July 2013; in revised form: 28 August 2013 / Accepted: 3 September 2013 / Published: 10 September 2013

\begin{abstract}
A distribution system was designed and operated by considering unidirectional power flow from a utility source to end-use loads. The large penetrations of distributed generation (DG) into the existing distribution system causes a variety of technical problems, such as frequent tap changing problems of the on-load tap changer (OLTC) transformer, local voltage rise, protection coordination, exceeding short-circuit capacity, and harmonic distortion. In view of voltage regulation, the intermittent fluctuation of the DG output power results in frequent tap changing operations of the OLTC transformer. Thus, many utilities limit the penetration level of DG and are eager to find the reasonable penetration limits of DG in the distribution system. To overcome this technical problem, utilities have developed a new voltage regulation method in the distribution system with a large DG penetration level. In this paper, the impact of DG on the OLTC operations controlled by the line drop compensation (LDC) method is analyzed. In addition, a generalized determination methodology for the DG penetration limits in a distribution substation transformer is proposed. The proposed DG penetration limits could be adopted for a simplified interconnection process in DG interconnection guidelines.
\end{abstract}


Keywords: on-load tap changer (OLTC); distributed generation (DG); line drop compensation (LDC); penetration limits; interconnection standards/guidelines

\section{Introduction}

It is well known that the interconnections of distributed generation (DG) to an existing distribution network cause unfavorable technical problems, which include power quality problems such as slow/fast voltage changes, harmonic distortions, protection coordination, and exceeding the rating of power equipment. Therefore, a DG interconnection standard has been established to prevent these problems and DG interconnection should satisfy certain requirements [1]. Most existing distribution systems have been operated with uncontrolled DG units to maintain the power quality and reliability within admissible operation ranges.

The penetration level of DGs for a particular voltage level should be limited to maintain admissible power quality and reliability [2-7]. Many regulatory committees and utilities have recommended DG interconnection procedures to guarantee a reasonable penetration level of DGs in distribution systems [8-12]. In practice, many DG interconnection procedures adopt different $\%$ rules for simplified DG interconnection procedures. However, they unfortunately cannot provide any suitable documentation of technical studies or background information to determine these rules.

Generalized methodologies for simple rules are required to determine the reasonable penetration level of DGs in distribution systems. In general, voltage regulation impacts by the DGs are considered as the most critical issues in modern radial distribution systems [13]. In this paper, a generalized methodology for the determination of a simple rule in view of voltage regulation in a distribution substation transformer (bank) is proposed. In addition, a simple rule is introduced for DG penetration limits in view of voltage regulation in a distribution substation transformer.

\section{Impact of Distributed Generation (DG) on On-Load Tap Changer (OLTC) Operations}

\subsection{Representation of the Line Drop Compensation (LDC) Method of OLTC Transformer}

The voltage management of radial distribution is designed based on unidirectional power flow. The main voltage control device in a distribution substation is an on-load tap changing (OLTC) transformer, which can change the tap position under load conditions [14]. In general, the OLTC transformers in a distribution substation adopt the line drop compensation (LDC) method to compensate the distribution voltage drop and to maintain the customers' terminal voltage within permissible limits. The control mechanism and voltage regulation concept of the OLTC transformer by the LDC method are shown in Figure 1. As shown in this Figure, the voltage profiles at the HV distribution line are dominated by the main transformer OLTC tap control using the LDC method with respect to the load change. In the LDC method, the OLTC regulates the sending-end voltage (SEV) or the distribution bus voltage to maintain the voltage of the high-voltage (HV) distribution line within the designated ranges by maintaining the voltage on the center point at which a load concentrates at an optimal voltage level. 
Figure 1. On-load tap changing (OLTC) transformer control schemes by line drop compensation (LDC) method: (a) OLTC transformer control mechanism; and (b) illustration of voltage regulation by LDC method with load changes.

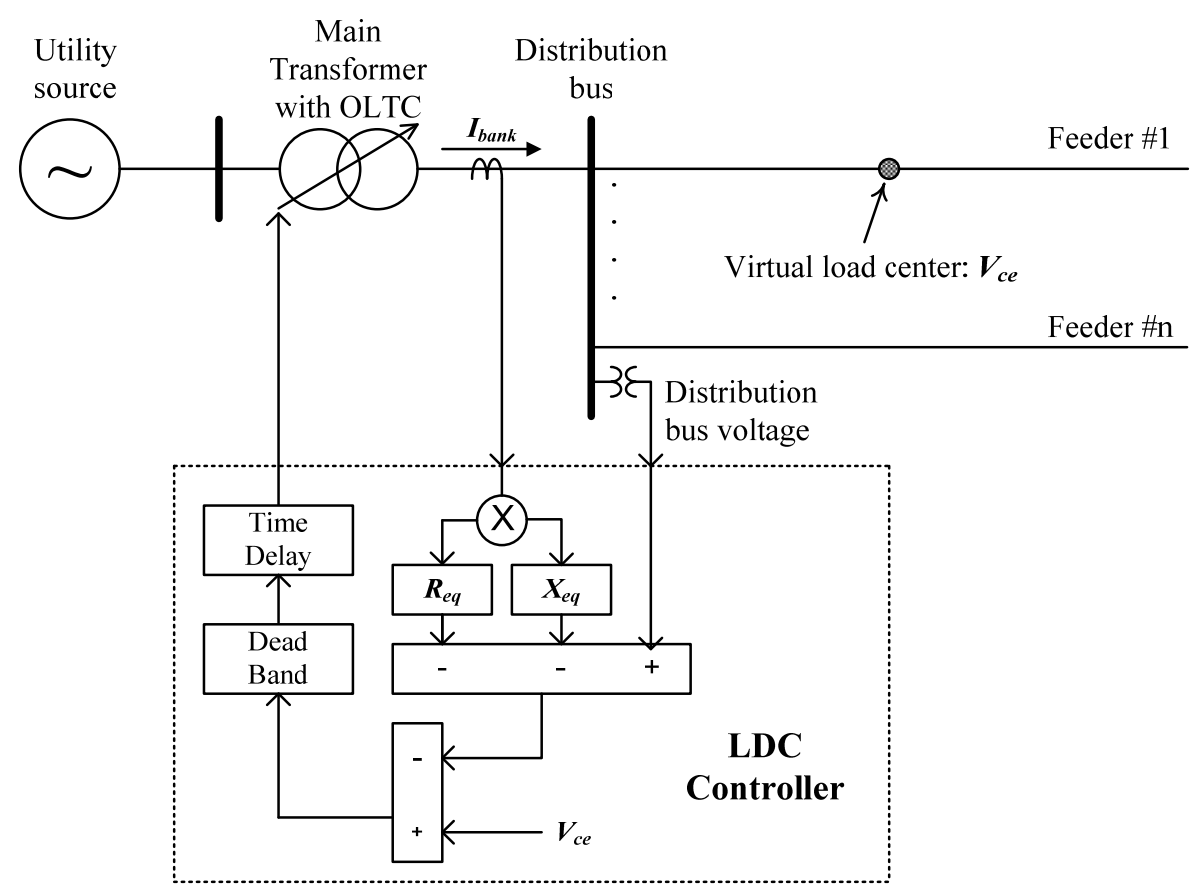

(a)

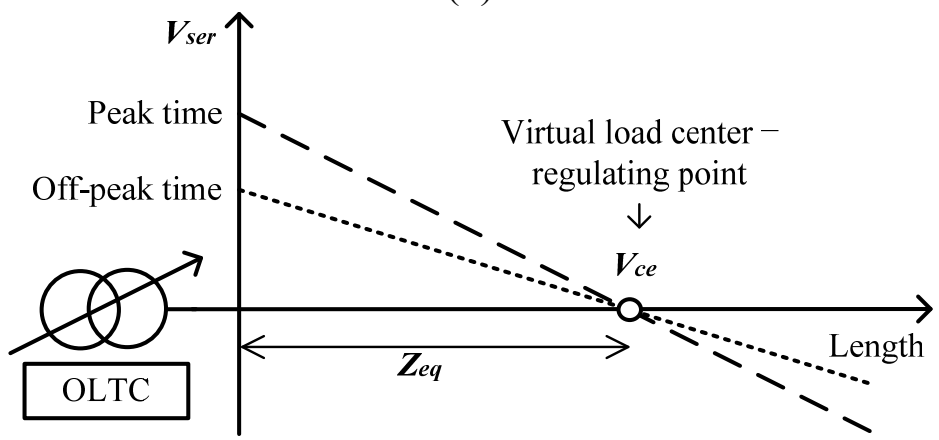

(b)

In the LDC method, the sending-end reference voltage (SERV) is given by $[15,16]$ :

$$
V_{s e r}=V_{c e}+Z_{e q} \times I_{b a n k}
$$

where $V_{\text {ser }}$ : sending-end reference voltage (SERV); $V_{c e}$ : reference voltage or voltage set value at virtual load center; $Z_{e q}$ : compensating impedance for voltage in line drop compensation (LDC) method; $I_{b a n k}$ : load current of the distribution substation transformer.

In Equation (1), $Z_{e q} \times I_{\text {bank }}$ represents the equivalent voltage drop of the distribution lines. In general, the LDC control method employs time delay and dead band to prevent frequent and unnecessary tap movements $[15,16]$. In the steady-state, SEV can be determined by:

$$
V_{\text {se }}=V_{\text {tap } . k}-Z_{k} \times I_{\text {bank }}
$$


where $V_{s e}$ : sending-end voltage (SEV); $V_{\text {tap }, k}$ : secondary voltage of the OLTC transformer when a tap is located at the $k$-th position; $Z_{k}$ : impedance of the OLTC transformer when a tap is located at the $k$-th position.

The LDC controller employs a proper time delay and dead band to prevent frequent and unnecessary tap movements. For the time delay, electric power companies have their own reference values, generally ranging from 1 to $4 \mathrm{~min}$. The dead band value is usually set at a value above the voltage adjustment range per tap. For example, Korea electric power company (KEPCO) sets the value within a range of $1 \%-2 \%$. The SEV can be maintained by:

$$
V_{\text {ser }}-d b<V_{s e}<V_{\text {ser }}+d b
$$

where $d b:$ dead band of LDC controller.

The relationship between the SERV and the SEV at distribution network is illustrated in Figure 2. The SEVs are maintained within the SERV plus/minus dead band. When a load id decreasing, the SERV value is lowered and SEV value is raised. In contrast, when a load id increasing, the SERV value is raised and SEV value is lowered.

Figure 2. Relationship between the SERV and the SEV at distribution network.

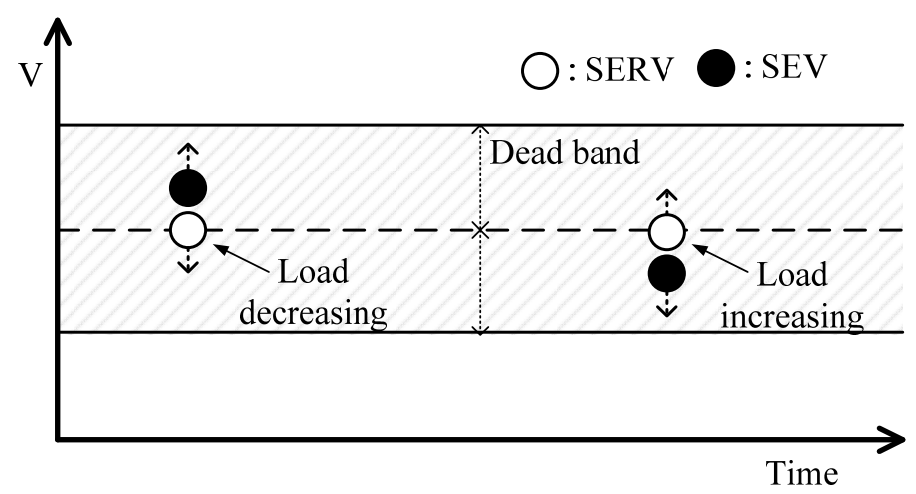

A small dead band value of less than $1 \%$, or a voltage interval between taps, results in repeatable unnecessary tap changing operations during transient load changes. Otherwise, a value of the dead band larger than $3 \%$ results in poor voltage regulation performance of the distribution lines [17].

\subsection{Impact of DG on LDC Control Method}

If DGs are connected to a distribution system, the load current of the distribution substation transformer $\left(I_{\text {bank }}\right)$ is changed to the following:

$$
I_{b a n k}^{\prime}=I_{b a n k}-\sum I_{D G}
$$

where $I_{b a n k}^{\prime}$ : load current of the distribution substation transformer with DGs; $\sum I_{D G}$ : sum of injected current by DGs.

In Equation (4), it is clear that the load current of a distribution substation transformer with DGs (i.e., $I_{\text {bank }}^{\prime}$ ) is decreased due to the interconnection operations of the DG, which can affect the calculation of the equivalent voltage drop in the LDC controller. Therefore, the SERV with the interconnection operations of DGs becomes: 


$$
V_{s e r}^{\prime}=V_{c e}+Z_{e q} \times I_{b a n k}^{\prime}
$$

where $V_{\text {ser }}^{\prime}$ :SERV with the interconnection of DGs.

Subtracting Equation (1) from Equation (5), the variation of the SERV with DGs can be obtained by:

$$
\begin{aligned}
\Delta V_{\text {ser }} & =\left|V_{\text {ser }}-V_{\text {ser }}^{\prime}\right| \\
& =\left(V_{c e}+Z_{e q} \times I_{\text {bank }}\right)-\left(V_{c e}+Z_{e q} \times I_{b a n k}^{\prime}\right) \\
& =Z_{e q} \times\left(I_{b a n k}-I_{b a n k}^{\prime}\right) \\
& =Z_{e q} \times \sum I_{D G}
\end{aligned}
$$

where $\Delta V_{\text {ser }}$ : variation of the SERV due to the interconnection of DGs.

For simplified analysis of the SERV with DGs, the DGs can be integrated into the distribution bus without much error $[17,18]$. The equivalent distribution system with DGs to analyze the variation of the SERV with DGs is shown in Figure 3 [17].

Figure 3. The equivalent distribution network with DGs.

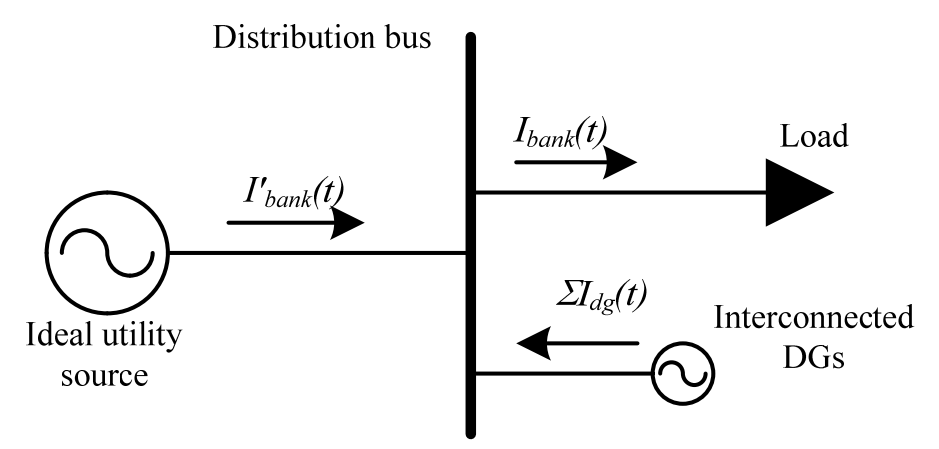

The $\Delta V_{\text {ser }}$ is analyzed for a sample case. For a sample case, the $Z_{e q}$ is $0.075+\mathrm{j} 0.039$ (p.u.). The changes in $\Delta V_{\text {ser }}$ vs. power factor and reverse power of DGs are shown in Figure 4, where it can be seen that the $\Delta V_{\text {ser }}$ of the distribution system with a lagging power factor of DG is larger than that of a distribution system with a leading power factor of DG. The leading power factor of DG absorbs the reactive power from the utility source [17].

Figure 4. Illustration of the changes in $\Delta V_{\text {ser }}$ vs. power factor and capacity of DGs.

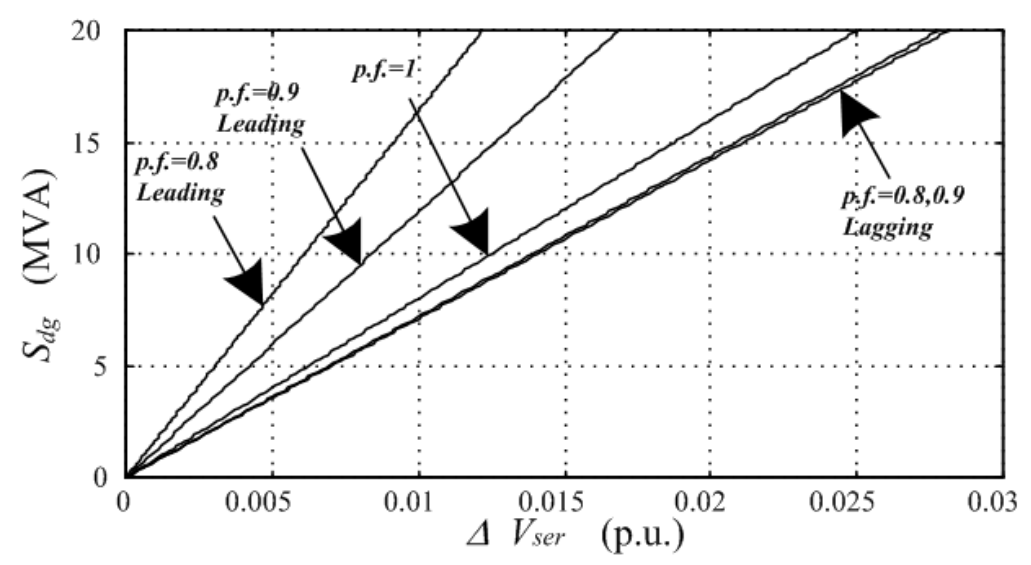


In the same manner, the SEV with DGs becomes:

$$
V_{s e}^{\prime}=V_{t a p, k}-Z_{k} \times I_{b a n k}^{\prime}
$$

where $V_{s e}^{\prime}:$ SEV with the interconnection of DGs.

Subtracting Equation (2) from Equation (7), the variation of the SEV with DGs can be obtained by:

$$
\begin{aligned}
\Delta V_{\text {se }} & =\left|V_{\text {se }}-V_{\text {se }}^{\prime}\right| \\
& =\left(V_{\text {tap }, k}+Z_{k} \times I_{\text {bank }}\right)-\left(V_{\text {tap }, k}+Z_{k} \times I_{\text {bank }}^{\prime}\right) \\
& =Z_{k} \times\left(I_{\text {bank }}-I_{\text {bank }}^{\prime}\right) \\
& =Z_{k} \times \sum I_{D G}
\end{aligned}
$$

where $\Delta V_{s e}$ : variation of the SEV due to the interconnection of DGs.

In Equation (8), it can be seen that the variations of the SEV can be dominated by the output power variation of the interconnected DGs. The unnecessary tap changing operations will be occurred when the differences between the variations of the SEV and the variations of the SERV are larger than the dead band, i.e., $\left|V_{\text {ser }}^{\prime}-V_{s e}^{\prime}\right|>d b$.

\section{DG Penetration Limits in View of Voltage Regulation at Distribution Substation Transformer Level}

\subsection{Generalized Formulation}

The DGs such as photovoltaic generation or wind power generation have intermittent output characteristics, which are disturbances in the conventional control schemes of distribution voltage control devices such as the OLTC transformer. The frequent output fluctuations of the DGs cause a variation of the SERV and the SEV. As a result, frequent tap changing operation problems of the OLTC transformer can appear in a distribution system with DGs. This shortens the lifetime of the OLTC transformer, and causes voltage fluctuation in the entire distribution system. Therefore, the interconnection capacity of DGs should be limited at the distribution substation transformer level to prevent frequent and unnecessary tap changing operations of the OLTC transformer. This criterion can be expressed by:

$$
\left|V_{s e r}^{\prime}-V_{s e}^{\prime}\right|<d b
$$

For simplicity, the impedance change of the OLTC transformer with the tap position can be neglected. Thus, it can be assumed that the impedance of the OLTC transformer with a specified tap position is equal to the leakage impedance of the OLTC transformer, i.e., $Z_{M T R} \cong Z_{k}$. The variation of the SEV with DGs of Equation (8) can be rewritten as follows:

$$
\Delta V_{s e} \cong Z_{M T R} \times \sum I_{D G}
$$

where $Z_{M T R}$ : leakage impedance of the OLTC transformer.

Assuming that the load current is constant, the SERV tends to decrease with $V_{\text {ser }}^{\prime}<V_{\text {ser }}$, while the SEV tends to increase with $V_{s e}^{\prime}>V_{s e}$. Rearranging Equation (9) it becomes: 


$$
\left|V_{s e r}^{\prime}-V_{s e}^{\prime}\right|=\Delta V_{s e r}+\Delta V_{s e}=\left(Z_{e q}+Z_{M T R}\right) \times \sum I_{D G} \leq d b
$$

As a result, to prevent frequent tap changing operations of the OLTC transformer, the difference between the SERV and the SEV should not be beyond the dead band of the LDC controller. Thus, in view of OLTC voltage regulation, the acceptable accumulated capacity of DGs can be determined by:

$$
\sum I_{D G} \leq \frac{d b}{\left(Z_{e q}+Z_{M T R}\right)}
$$

\subsection{Further Simplification for Simplified Interconnection Process}

In Equation (8), comparing the resistance component and the reactance component of the impedance of the OLTC transformer, the reactance component is much larger than resistance component, or $X_{M T R} \gg R_{M T R}$. In general, the grid interactive DGs are operated with a unity power factor. From these assumptions, $\left(R_{M T R} \cong 0, \sin \theta=0\right)$, the variation of the SEV with DGs can be rearranged as:

$$
\Delta V_{s e}=\left(R_{M T R} \cos \theta \pm X_{M T R} \sin \theta\right) \times\left|\sum I_{D G}\right|=R_{M T R} \times\left|\sum I_{D G}\right| \approx 0
$$

where $\cos \theta$ : aggregate power factor of DGs.

From Equation (13), it can be seen that SEV with DGs remains constant when the interconnected DGs are operating with a unity power factor. Thus, the variation of the SERV with DGs of Equation (6) can be a critical factor to determine the acceptable accumulated capacity of DGs in view of OLTC voltage regulation at the distribution substation transformer level.

Neglecting the variation of the SEV with DGs, the acceptable cumulative capacity of DGs in view of OLTC voltage regulation is given by:

$$
\sum I_{D G} \leq \frac{d b}{Z_{e q}}
$$

Therefore, the acceptable cumulative capacity of DGs can be determined by the compensating impedance and the dead band of the LDC controller. Equation (14) shows that a larger value of the dead band and a smaller value of the compensating impedance result in a large penetration level of the DGs for maintaining reasonable voltage regulation performance of the OLTC transformer.

\section{Simple Rule in View of Voltage Regulation at Distribution Substation Transformer Level}

\subsection{General Approach}

The frequent and unnecessary tap changing operations of the OLTC transformer could be prevented by restricting the cumulative penetration level of the DGs below specified limits. This can be used as a simple rule for a simplified interconnection process of DG interconnection procedures.

The compensating impedance represents the voltage drop characteristics of the distribution lines in a distribution system. Thus, the compensating impedance of the distribution system with long distribution lines or large loads should be larger than that of short distribution lines or small loads. From Equation (1), the compensating impedance can be determined by the load current of the 
substation transformer and the SERV. The compensating impedance should be chosen to regulate the voltage drop of the distribution lines during certain periods of times. In order to determine the compensating impedance for a specified distribution system, the optimal SERVs corresponding to load currents is first obtained from the power flow, and then the compensating impedance is chosen to minimize the voltage regulation errors [19]. Furthermore, the compensating impedance has to be updated with changes of the distribution configuration and load increment and expansion.

In practice, the compensating impedance and the load center voltage can be simply calculated from the maximum and the minimum SERV employed by a utility distribution company:

$$
\begin{gathered}
Z_{e q}=\frac{V_{s e r}-V_{c e}}{I_{b a n k}}=\frac{V_{s e r}^{\max }-V_{c e}}{I_{b a n k}^{\max }} \\
Z_{e q}=\frac{V_{s e r}-V_{c e}}{I_{b a n k}}=\frac{V_{s e r}^{\min }-V_{c e}}{I_{b a n k}^{\min }}
\end{gathered}
$$

where $V_{\text {ser }}^{\max }$ : maximum SERV at maximum load current; $V_{\text {ser }}^{\min }:$ minimum SERV at minimum load current; $I_{\text {bank }}^{\max }:$ maximum load current; $I_{\text {bank }}^{\min }$ : minimum load current.

In the KEPCO distribution network, the maximum allowable voltage drop of HV distribution is $5 \%$, the nominal tap of a low-voltage (LV) distribution transformer is $104.5 \%$, and the maximum allowable voltage drop of an LV distribution network is $10 \%$. According to these technical specifications, the maximum and the minimum SERV in the KEPCO distribution network are 1.04 (p.u.) and 0.99 (p.u.), respectively.

For simplicity, the minimum load current of the distribution substation transformer is assumed to be zero. The maximum load current reaches the rated capacity of the distribution substation transformer. The compensating impedance and the load center voltage can be calculated from Equations (15) and (16). The $V_{c e}$ is calculated as 0.99 (p.u.), and the $Z_{e q}$ is 0.05 (p.u.).

Setting a criterion based on $1 \%$ variation of the SERV with DGs, the acceptable cumulative capacity of DGs that is represented by the ratio of the maximum load current is calculated as follows:

$$
\frac{\sum I_{D G}}{I_{\text {bank }}^{\max }}=\frac{\sum S_{D G}}{S_{\max }}=\frac{0.01}{0.05}=20 \%
$$

where $\sum S_{D G}$ : maximum (cumulative) rated capacity of the DGs; $S_{\max }$ : rated capacity of the distribution substation transformer.

From Equations (15) through Equation (17), it can be seen that the critical factors for the determination of the DG penetration level are the voltage drop characteristics and the compensating impedance of the specified distribution network. The acceptable cumulative capacity of DGs that is represented by the ratio of the maximum load current with different specifications of the KEPCO distribution system are listed in Table 1 . Three different load ratios $\left(I_{\min } / I_{\max }\right)$ are considered in Table 1.

In Table 1 , the minimum value of the $I_{\min } / I_{\max }$ is determined from the statistical load data of the KEPCO distribution system, and the maximum load current is the same as the rated load current of the OLTC transformer. The maximum and minimum SERVs for the different load ratios are chosen to minimize the voltage regulation errors [19]. The specifications of the three different cases are summarized as follows: 
Case I: $I_{\min } / I_{\max }=1 / 5$, maximum SERV $=1.04$ (p.u.), minimum SERV $=1.0000$ (p.u.), reference voltage $\left(V_{c e}\right)=0.99$ (p.u.), compensating impedance $\left(Z_{\text {eq }}\right)=0.05$ (p.u.).

Case II: $I_{\min } / I_{\max }=1 / 4$, maximum SERV $=1.04$ (p.u.), minimum SERV $=1.0125$ (p.u.), reference voltage $\left(V_{c e}\right)=1.0033$ (p.u.), compensating impedance $\left(Z_{\text {eq }}\right)=0.0367$ (p.u.).

Case III: $I_{\min } / I_{\max }=1 / 3$, maximum SERV $=1.04$ (p.u.), minimum $S E R V=1.0167$ (p.u.) reference voltage $\left(V_{c e}\right)=1.0050$ (p.u.), compensating impedance $\left(Z_{\text {eq }}\right)=0.0350$ (p.u.).

Table 1. The simple rule at the distribution substation transformer level with different maximum/minimum load ratios and different dead band (power factor of DG = unity power factor).

\begin{tabular}{ccc}
\hline Cases & Dead band $(\boldsymbol{d b})$ & \% Rule \\
\hline \multirow{3}{*}{ Case I } & $1.00 \%$ & $20.0 \%$ \\
& $1.25 \%$ & $25.0 \%$ \\
& $1.50 \%$ & $30.0 \%$ \\
\hline \multirow{3}{*}{ Case II } & $1.00 \%$ & $27.3 \%$ \\
& $1.25 \%$ & $34.1 \%$ \\
& $1.50 \%$ & $40.9 \%$ \\
\hline \multirow{2}{*}{ Case III } & $1.00 \%$ & $28.6 \%$ \\
& $1.25 \%$ & $35.7 \%$ \\
\hline
\end{tabular}

From the results of Table $1,20 \%-25 \%$ of the rated loads of the distribution substation transformer could be adopted for the simple rule. This is $12 \mathrm{MW}$ to $15 \mathrm{MW}$ for the typical 60-MVA main transformers of a substation. The advantages of this approach are: (1) a simplified interconnection process could be applied for the interconnection capacity of a DG applicant less than the specified \% rule; and (2) the technical evaluation is very simple, in that there is no detailed interconnection study in this process for the interconnection connection capacity of the DG applicant less than the specified \% rule. From the results of Table 1, the 20\%-25\% DGs penetration level of the distribution substation transformer capacity seems to be a reasonable penetration level for a simplified interconnection process. It can be applied to most distribution systems designed with the planning specifications in the KEPCO distribution system.

\subsection{Simple Approach}

With the DGs operate on a unity power factor basis, only the fluctuation volume of the SERV remains according to Equation (6). According to this equation, a larger compensating impedance of the LDC controller corresponds to greater increases in fluctuation of the SERV for DGs with the same capacity. The interconnection capacity of DGs calculated using Equation (6) by reflecting the largest compensating impedance in the distribution system, can serve as a simple guideline for determining whether or not it is possible to connect the substation transformer without any specific technical calculation.

For a simple approach, it can be assumed that voltage drop of the LV distribution lines has maximum values when the load current of the distribution substation transformer reaches its maximum 
value $\left(I_{\max }\right)$. At this time, the SERV must have its maximum value. It is note that the maximum load current of the distribution substation transformer is not equal to the rated capacity of the distribution substation transformer for a simple approach. On the other hand, It can be assumed that voltage drop of the LV distribution lines has minimum values when the load current of the distribution substation transformer is equal to no load conditions, i.e., $I_{\min }=0$. At this time, the SERV must have its minimum value. Thus, reference voltage $\left(V_{c e}\right)$ is equal to the minimum SERV.

With these assumptions, the largest compensating impedance of the specified distribution substation transformer can be obtained from the maximum load current, maximum SERV, and minimum SERV. As mentioned before, the maximum and the minimum SERV in the KEPCO distribution network are 1.04 (p.u.) and 0.99 (p.u.), respectively.

Thus, the largest compensating impedance is calculated as follows:

$$
Z_{e q}=\frac{V_{\text {ser }}-V_{c e}}{I_{\text {bank }}} \cong \frac{1.04-0.99}{I_{\max }}=\frac{0.05 \sqrt{3} \mathrm{~V}}{S_{\max }^{\prime}}
$$

where $S_{\max }^{\prime}$ : maximum load of the distribution substation transformer.

Assuming that the dead band generally set in Equation (12) is $1 \%$ (0.01 p.u.), and the value of $Z_{M T R} \approx 0$ is as mentioned above, the maximum interconnection capacity of the DGs can be determined by:

$$
\sum S_{D G}=\sqrt{3} V \sum I_{D G}=\frac{0.01 \sqrt{3} V}{Z_{e q}}
$$

Substituting Equation (18) for Equation (19), the maximum (cumulative) interconnection capacity of DGs assuming the largest compensating impedance is calculated as follows:

$$
\sum S_{D G}=\frac{0.01 \sqrt{3}}{0.05 \sqrt{3}} S_{\max }^{\prime}=\frac{1}{5} S_{\max }=20 \% \times S_{\max }^{\prime}
$$

From Equation (20), it can be seen that the 20\% DGs penetration level of the maximum load of the distribution substation transformer seems to be a reasonable penetration level for a simplified interconnection process.

\subsection{Simplified Interconnection Process at Distribution Substation Transformer Level}

In the proposed general and simple approach, it can be seen that the reasonable interconnection capacity of DGs in the KEPCO distribution substation transformer levels is about $20 \%-25 \%$ of the maximum load current or rated capacity of the distribution substation transformer. By restricting the interconnection capacity of DGs below $20 \%-25 \%$ of the maximum load or the rated capacity of the distribution substation transformer, frequent tap changing operations controlled by LDC can be prevented.

This may be used as a simple interconnection process of the DG interconnection guideline on a distribution substation transformer to evaluate the interconnection capacity of DGs. The capacity of $20 \%-25 \%$ or less of the maximum load or the rated capacity of the distribution substation transformer serves as a criterion for approving such connections without any specific technical calculation. If the interconnection capacity of DGs is larger than $20 \%-25 \%$ of the maximum load or the rated capacity of the distribution substation transformer, it can be evaluated based on Equation (12) using the actual 
LDC setting values of the specified distribution system. The simplified DG interconnection process for the KEPCO distribution substation transformer level is illustrated in Figure 5.

Figure 5. Simplified DG interconnection process for KEPCO distribution substation transformer level.

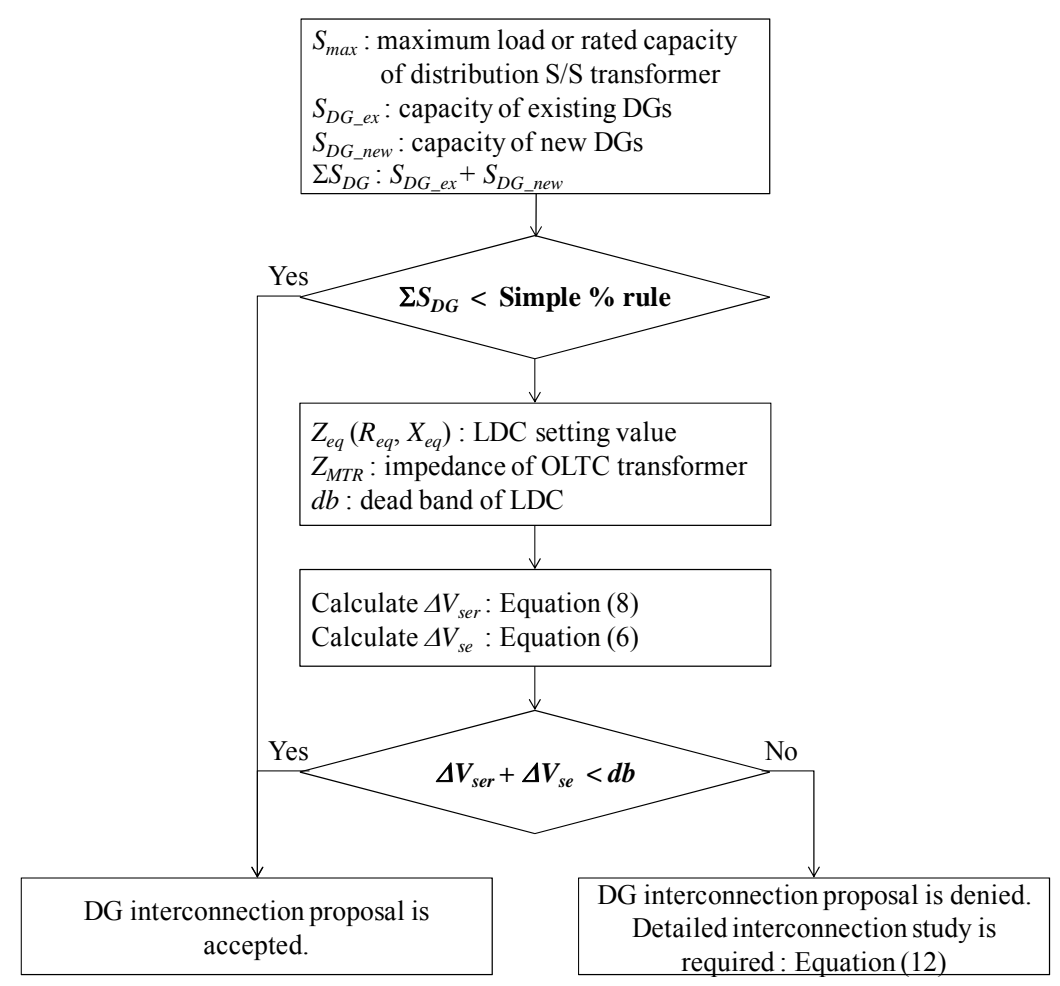

In the detailed interconnection process, a very simple technical solution is readjusting the compensating impedance of LDC $\left(Z_{e q}\right)$ to increase the interconnection capacity of DGs at the distribution substation transformer levels without any network reinforcements. Also, changing the normal operation conditions for the power factor of the DGs can be an alternative technical solution [18]. However, this results in local voltage problems in distribution lines. In order to overcome the local voltage raise problems at the HV/LV distribution lines with large penetration of DGs, the autonomous or centralized control of DG reactive power should be adopted [20-22]. On the other hand, the centralized/decentralized voltage management schemes of the voltage control devices, such as OLTC transformer, energy storage system (ESS), and reactive power control of the DGs, should be adopted in the future distribution network to optimize the voltage profiles of the entire distribution networks $[15,23,24]$.

\section{Conclusions}

In this paper, a generalized methodology to evaluate the penetration level of DGs at the distribution substation transformer level in view of OLTC voltage regulation has been presented. Generalized formulations were introduced to evaluate the reasonable interconnection capacity of the DGs at the distribution substation transformer level. These formulations can be used for a detailed interconnection study process for distribution systems which adopt OLTC transformers and LDC control methods. 
For practical application of the proposed methodology, a simplified methodology and related formulations were proposed. Simply by using these formulations, a simple \% rule for the different specifications of different specified distribution systems could be determined in view of voltage regulation at the distribution substation transformer level. The determined simple \% rule would be seamlessly adopted in the simplified interconnection process of DG interconnection procedures. It is expected that the proposed methodologies and formulations will be useful for utility engineers and consultants in evaluating the penetrations level of DGs at the distribution substation transformer level in view of voltage regulation.

\section{Conflicts of Interest}

The authors declare no conflict of interest.

\section{References}

1. Institute of Electrical and Electronics Engineers (IEEE). IEEE Standard for Interconnecting Distributed Resources with Electric Power Systems; IEEE Press: New York, NY, USA, 2003.

2. Kim, T.-E.; Kim, J.-E. A Method for Determining the Introduction Limit of Distributed Generation System in Distribution System. In Proceedings of the IEEE Power Engineering Society Summer Meeting, Vancouver, BC, Canada, 15-19 July 2001; pp. 456-461.

3. Bhowmik, A.; Maitra, A.; Halpin, S.M.; Schatz, J.E. Determination of allowable penetration levels of distributed generation resources based on harmonic limit considerations. IEEE Trans. Power Deliv. 2003, 18, 619-624.

4. Morren, J.; de Hann, S.W.H. Maximum Penetration Level of Distributed Generation without Voltage Limits. In Proceedings of the 20th International Conference and Exhibition on Electricity Distribution (CIRED 2009), Prague, Czech Republic, 8-11 June 2009.

5. Thong, V.V.; Dommelen, D.V.; Belmans, R. Penetration Level of Distributed Energy Resources with Anti-Islanding Criteria and Secure Operation of Power System. In Proceedings of the IEEE Power Engineering Society General Meeting, Montreal, QC, Canada, 18-22 June 2006.

6. Miller, N.; Ye, Z. Report on Distributed Generation Penetration Study; National Renewable Energy Laboratory: Golden, CO, USA, 2003.

7. Ayres, H.M.; Freitas, W.; de Almeida, M.C.; da Silva, L.C.P. Method for determining the maximum allowable penetration level of distributed generation without steady-state voltage violations. IET Gener. Transm. Distrib. 2010, 4, 495-508.

8. California Energy Commission Rule 21 Working Group. California Electric Rule 21 Supplemental Review Guideline, California Distributed Energy Resource Guide; California Energy Commission: Sacramento, CA, USA, 2005.

9. Federal Energy Regulatory Commission (FERC). Small Generator Interconnection Procedures (SGIP) and Small Generator Interconnection Agreement (SGIA); FERC: Washington, DC, USA, 2006.

10. Interstate Renewable Energy Council (IREC). The Model Interconnection Standards and Procedures for Small Generator Facilities (IREC Procedures); IREC: Latham, NY, USA, 2006. 
11. National Association of Regulatory Utility Commissioners (NARUC). Small Generation Resource Interconnection Procedures (NARUC Procedures); NARUC: Washington, DC, USA, 2008.

12. Bundesverband der Energie- und Wasserwirtschaft (BDEW). Generating Plants Connected to the Medium-Voltage Network; BDEW: Berlin, Germany, 2008.

13. Katiraei, F.; Agüero, J.R. Solar PV integration challenges. IEEE Power Energy Mag. 2011, 9, $62-71$.

14. Calovic, M.-S. Modeling and analysis of under load tap changing transformer control system. IEEE Trans. Power Appar. Syst. 1984, 107, 1909-1915.

15. Choi, J.-H.; Kim, J.-C. Advanced voltage regulation method of power distribution systems interconnected with dispersed storage and generation systems. IEEE Trans. Power Deliv. 2001, 16, 329-334.

16. Choi, J.-H.; Moon, S.-I. The dead band control of LTC transformer at distribution substation. IEEE Trans. Power Syst. 2009, 24, 319-326.

17. Choi, J.-H. Operation and Integration Strategies of Dispersed Generations in Power Distribution System. Ph.D. Thesis, Soongsil University, Seoul, Korea, 2001.

18. Korea Electric Power Company. A Study on the New Technical Guidelines for Interconnection Capacity of Distributed Generations in Distribution System (Korean); Korea Electric Power Research Institute (KEPRI): Deajeon, Korea, 2011.

19. Choi, J.-H.; Kim, J.-C. The online voltage control of ULTC transformer for distribution voltage regulation. Int. J. Electr. Power Energy Syst. 2001, 23, 91-98.

20. Choi, J.-H.; Jung, W.-W.; Song, I.-K. Interconnection Guidelines and Control Coordination Reactive Power Support Functions of Distributed Energy Resources. In Proceedings of the 21th International Conference on Electricity Distribution (CIRED), Frankfurt, Germany, 6-9 June 2011.

21. Zhang, B.S.; Lam, A.Y.S.; Dominguez-Garcia, A.; Tse, D. Optimal Distributed Voltage Regulation in Power Distribution Networks. Cornell University Library Web Page. Available online: http://arxiv.org/abs/1204.5226v1 (accessed on 23 April 2012).

22. Tedesco, F.; Casavola, A. A Distributed Command Governor Approach for Voltage Regulation in Medium Voltage Power Grids with Distributed Generation. In Proceedings of the 2013 American Control Conference (ACC), Washington, DC, USA, 17-19 June 2013.

23. Choi, J.-H.; Ahn, S.-J.; Jung, W.-W.; Chu, C.-M.; Song, I.-K. Technical Solution/Recommendations for Large Penetration of DGs in KEPCO Distribution Network. In Proceedings of the International Conference on Electricity Distribution (CIRED), Lisbon, Portugal, 29-30 May 2012.

24. Calderaro, V.; Galdi, V.; Piccolo, A.; Massa, G. Optimal Fuzzy Controller for Voltage Control in Distribution Systems. In Proceedings of the 11th International Conference on Intelligent Systems Design and Applications (ISDA), Cordoba, Argentina, 22-24 November 2011; pp. 1282-1287.

(C) 2013 by the authors; licensee MDPI, Basel, Switzerland. This article is an open access article distributed under the terms and conditions of the Creative Commons Attribution license (http://creativecommons.org/licenses/by/3.0/). 